\title{
Restricted Expression of the Actin-Regulatory Protein, Tropomyosin, Defines Distinct Boundaries, Evaginating Neuroepithelium, and Choroid Plexus Forerunners during Early CNS Development
}

\author{
Kelley Nicholson-Flynn, Sarah E. Hitchcock-DeGregori, and Pat Levitt \\ Department of Neuroscience and Cell Biology, Robert Wood Johnson Medical School, University of Medicine and \\ Dentistry of New Jersey, Piscataway, New Jersey 08854
}

In the hindbrain, rhombomeres represent morphological units that develop characteristic, segment-specific structures. Similar segments, known as prosomeres, have been proposed to exist in the forebrain. The neuroepithelial cells of the sharp boundary regions that form the borders between many segments often exhibit distinct shapes, reflecting unique cytoskeletal organization. The present investigation examined the expression of one family of actin-binding, regulatory proteins, the tropomyosins (TM), in boundaries. We found that high molecular weight TMs selectively concentrate in boundary cells and other neuroepithelial zones that exhibit unique cell shapes and movements. Specific TM expression is found at hindbrain boundaries as early as embryonic day 10 in the rat, whereas rhombomeres themselves were TM-negative. Highly restricted TM localization also defined some prosomere boundaries in the early forebrain, particularly those exhibiting unique cell shapes.
Furthermore, several regions of the neuroepithelium that evaginate are TM-immunoreactive, including tuberal and preoptic neuroepithelium. Most striking, a subpopulation of neuroepithelial cells in the medial telencephalic wall expresses TM, apparently marking the neuroepithelial region that gives rise to the choroid plexus at least $2 \mathrm{~d}$ before its formation. This suggests that the medial cerebral wall is not entirely dedicated to generating cells that comprise allocortex. TM expression in the choroid plexus is maintained through initial evagination and appearance in all ventricles. The spatially restricted expression of TMs implicates that this actin-binding protein is involved in the dynamic regulation of cell shape or motility associated with boundary formation and morphogenesis of the neuroepithelium during critical stages of brain development.

Key words: tropomyosin; rhombomere; prosomere; choroid plexus; segmentation; cytoskeleton; cell shape; cell fate
During CNS development in vertebrates, the neuroepithelium becomes divided into morphologically distinct segments. Transient hindbrain structures, known as rhombomeres, are units of cell lineage restriction in which cells of one segment rarely cross into an adjacent one (Fraser et al., 1990; Birgbauer and Fraser, 1994). Similarly, forebrain neuroepithelium has been postulated to be segmented into prosomeres or neuromeres (Figdor and Stern, 1993; Rubenstein et al., 1994), based on differential expression of well defined combinations of transcription factors and intercellular signaling molecules (Puelles and Rubenstein, 1993; Papalopulu, 1995). Furthermore, limits of expression of homeobox-containing transcription factors, hox genes, obey rhombomere boundaries, and it is thought that the set of hox genes expressed in an individual rhombomere provides positional identity (Krumlauf et al., 1993). There is increased immunoreactivity for L1, laminin (Lumsden and Keynes, 1989), and a peanut lectin-binding epitope (Layer and Alber, 1990) at boundaries, but none is unique to boundary cells.

The unusual shape of many boundaries and the morphogenetic

Received June 17, 1996; revised Aug. 13, 1996; accepted Aug. 16, 1996.

This work was supported by the American Heart Association, New Jersey Affiliate Pre-Doctoral Fellowship 95-FS-13 (K.N.-F.); GM36326 and HL35726 (S.E.H.-D.); and MH45507 (P.L.). We thank Dr. Kathie Eagleson for critical review of this manuscript, Yongmi An, Robin Hammell, and Dr. Norma Greenfield for providing TM proteins and peptides, and Dr. Itzhak Fischer for providing the MAP2 antibody.

Correspondence should be addressed to Dr. Pat Levitt, Department of Neuroscience and Cell Biology, Robert Wood Johnson Medical School, UMDNJ, 675 Hoes Lane, Piscataway, NJ 08854.

Copyright (C) 1996 Society for Neuroscience $0270-6474 / 96 / 166853-11 \$ 05.00 / 0$ movements that are associated with their formation suggest that regulation of the cytoskeleton plays an important role in establishing segmented patterns, perhaps by differential expression of contractile or structural proteins in boundary cells. One study by Guthrie et al. (1991) showed that actin, expressed by all neuroepithelial cells, exhibits a unique distribution in cells at rhombomere boundaries, suggesting a role for microfilaments in generating boundaries. Evidence exists for the role of microfilaments in cell shape changes associated with primary neurulation (Burnside, 1971; Karfunkel, 1971) and for folding of other epithelial sheets (Kam et al., 1991; Freemann et al., 1992). The actin cytoskeleton is likely to be a target of unique molecular regulation in regions of the neuroepithelium that actively undergo morphogenesis. This type of regulation must involve specific actin-binding proteins, but unique expression patterns of these proteins by cells undergoing morphogenesis have not been described in the developing CNS.

Tropomyosins (TM), a multigene family of coiled-coil, actin filament-binding proteins, regulate actomyosin function and stabilize the actin filament (Fujime and Ishiwata, 1971; Hitchcock et al., 1976; Bernstein and Bamburg, 1982; Fattoum et al., 1983; Broschat, 1989, 1990). The role of TM is well established in skeletal muscle contraction, but its function in nonmuscle cells is less clear (Lees-Miller and Helfman, 1991). In the rat, at least 14 isoforms of TM are present and differ in actin-binding affinity and actomyosin-regulatory function (Pittenger et al., 1994). Many of these isoforms, including the brain-specific $\alpha$-TM isoforms 
TMBr-1 and TMBr-3, exhibit tissue- and cell type-specific patterns of expression (Stamm et al., 1993; Had et al., 1994; Hannan et al., 1995; Weinberger et al., 1996). High molecular weight TMs bind actin strongly (Cote and Smillie, 1981; Matsumura and Yamashiro-Matsumura, 1985), and a downregulation of their expression accompanies the cytoskeletal disorganization induced by viral transformation (Hendricks and Weintraub, 1981). We report three major patterns of high molecular weight TM expression that demonstrate early parcellation of the neural tube into structurally and molecularly distinct regions corresponding to boundaries and areas undergoing morphogenetic movements. Thus, patterns of expression of high molecular weight TMs strongly suggest a role for the protein as a fundamental player in regulating cell shape during neuroepithelial morphogenesis.

\section{MATERIALS AND METHODS}

\section{Animals}

Timed pregnant Holtzman albino rats were obtained from Harlan Sprague Dawley. Rats were maintained under a $12 \mathrm{hr}$ light/dark cycle with free access to food and water. Detection of the sperm plug was considered embryonic day (E) 0 . Pregnant dams were anesthetized with Nembutal (i.p. injection, $50 \mathrm{mg} / \mathrm{kg}$ ). The uterine horns were dissected from the abdominal cavity and placed in HBSS. The extraembryonic membranes were removed, and embryos were staged according to crown-rump length (Olson and Seiger, 1972).

\section{Antibodies}

The distribution of one class of tropomyosins, the high molecular weight TMs (281-284 amino acids), was determined using the monoclonal antitropomyosin antibody TM311 (Sigma, St. Louis, MO). The microtubuleassociated protein 2 (MAP2) polyclonal antibody was generously provided by Dr. Itzhak Fischer (Fischer et al., 1987).

\section{Immunoblot analysis}

Epitope mapping. Approximately $500 \mathrm{ng}$ of the following proteins and peptides was applied to nitrocellulose membrane using a slot blot apparatus (Schleicher \& Schuell, Keene, NH): (1) recombinant rat striated $\alpha$-TM (Cho and Hitchcock-DeGregori, 1991); (2) recombinant rat smooth $\alpha$-TM (Cho and Hitchcock-DeGregori, 1991); (3) recombinant TM80, which contains the first 80 residues of exon 1a of chicken striated $\alpha$-TM; (4) TM32, an N-acetylated synthetic peptide that contains the first 32 residues of exon 1a of rat $\alpha$-TM (Greenfield et al., 1994); (5) TM35, an $\mathrm{N}$-acetylated synthetic peptide that corresponds to the N-terminal 14 residues of exon 1a of rat $\alpha$-TM followed by 21 amino acids of a modified coiled-coil sequence; (6) a synthetic peptide that corresponds to residues $30-44$ of exon $1 \mathrm{~b}$ of rat $\alpha$-TM; and (7) TM43, an N-acetylated synthetic peptide that corresponds to the first 14 residues of exon 1a of rat $\alpha$-TM, followed by a modified coiled-coil sequence (Greenfield and HitchcockDeGregori, 1993). Recombinant proteins and peptides, expressed in Escherichia coli, were unacetylated. Nonspecific binding was blocked with 5\% fetal bovine serum in PBS for $1 \mathrm{hr}$ before incubation in TM311, diluted 1:500 in 1\% dry milk in PBS. After washes in PBS, the membrane was incubated in goat anti-mouse IgG-horseradish peroxidase (HRP; Jackson ImmunoResearch, West Grove, PA) diluted at 1:2500, washed again in PBS, and immunoreactive bands were visualized using enhanced chemiluminescence (ECL; Amersham, Arlington Heights, IL).

Tissue lysate analysis. Tissue lysates of whole E16 and postnatal day (P) 10 brains were prepared in low-salt buffer, centrifuged at $1000 \times g$, and analyzed on $10 \%$ SDS-PAGE gels (Laemmli, 1970). Proteins were electroblotted onto nitrocellulose, blocked in 5\% fetal bovine serum in PBS, and incubated with TM311 at a dilution of 1:500 in followed by extensive washes in PBS and incubation in anti-mouse IgG-HRP (1:2500) in 1\% dry milk in PBS. Membranes were washed extensively in PBS and visualized by ECL.

\section{Immunocytochemistry}

Whole embryos (E10-E14) or brains (E15-E16) were fixed by immersion in $4 \%$ paraformaldehyde in phosphate buffer, $\mathrm{pH} 6.5$, for $2 \mathrm{hr}$, followed by immersion in $4 \%$ paraformaldehyde in phosphate buffer, $\mathrm{pH} 9.5$, overnight at $4^{\circ} \mathrm{C}$. The low- to high-pH fixation method (Berod et al., 1981) was found to be superior to conventional aldehyde fixation for immunolocalization of TM with the TM311 antibody (data not shown). The tissue was cryoprotected by immersion in 10,20, and $30 \%$ sucrose in $0.1 \mathrm{~m}$ phosphate buffer, $\mathrm{pH} 7.4$, at $4^{\circ} \mathrm{C}$. The tissue was frozen in O.C.T. mounting medium (Miles, Elkhart, IN) by immersion in the vapor phase of liquid nitrogen. Ten micrometer cryostat sections were collected on chrom alum-gelatin/poly-L-lysine-coated glass slides and were allowed to air dry at room temperature overnight. Sections were stored at $4{ }^{\circ} \mathrm{C}$ until use.

Immunolocalization of TM was performed by a modification of previously published methods (Ferri and Levitt, 1993). Sections were rehydrated in PBS, $\mathrm{pH}$ 7.2, and endogenous peroxidases were quenched by incubation in $0.5 \%$ hydrogen peroxide in methanol for $30 \mathrm{~min}$. Sections were washed extensively in PBS, followed by $0.3 \%$ Triton X-100 in Blotto (4\% Carnation dried milk in PBS) and Blotto without detergent. Sections were incubated overnight at room temperature in primary antibody diluted in Blotto. TM311 was diluted 1:500 in Blotto, and MAP2 was diluted 1:250. After three washes in $0.3 \%$ Triton X-100 in Blotto and three washes in Blotto alone, the sections were incubated with HRPconjugated goat anti-mouse IgG (for TM311) (Jackson ImmunoResearch) at a 1:100 dilution in Blotto for $1 \mathrm{hr}$. For double immunostaining with TM311 and MAP2, a cocktail of Cy3-conjugated goat anti-mouse IgG (TM311) and FITC-conjugated goat anti-rabbit IgG (MAP2) was used. Controls included incubating sections in either primary or secondary antibody alone. No immunostaining was present in control sections (data not shown). After extensive washes in PBS, HRP was visualized using a standard reaction with 3,3'-diaminobenzidine tetrahydrochloride as the substrate. Sections were washed extensively in PBS and dehydrated through a graded series of alcohols and Hemo-De (Fisher Scientific, Pittsburgh, PA), and coverslips were mounted with DPX mounting medium (BDH Limited, Poole, UK). Fluorescently labeled sections were washed and coverslips mounted with glycerol/PBS containing 5\% $n$-propyl-galate aqueous mounting medium. Immunoperoxidase-stained sections were photographed in bright-field illumination with a Leica photomicroscope on Kodak Technical Pan black and white film. Fluorescently double-immunolabeled sections were photographed using a $G / R$ double cube with P1600 Kodak color film. Alternate sections at each embryonic age were stained with cresyl violet for analysis of brain architecture with the aid of an atlas (Altman and Bayer, 1995). The terminology of embryonic zones is according to the Boulder Committee (1970).

\section{RESULTS}

\section{Characterization of the monoclonal anti-tropomyosin antibody TM311}

Although the TM311 monoclonal antibody has been used in a variety of studies, precise molecular characterization has not been reported. It has been suggested that TM311 recognizes an epitope encoded by exon 1a of the $\alpha$-TM gene, which encodes residues 1-38 (Stamm et al., 1993). We defined the epitope recognized by TM311 by slot blot analysis of proteins and peptides corresponding to various $\alpha$-TM gene products, containing sequences encoded by either of the alternate first $\alpha$-TM exons, 1a or $1 \mathrm{~b}$. Figure $1 A$ shows that TM311 bound to recombinant striated $\alpha$-TM (slot 1 ) and recombinant smooth $\alpha$-TM (slot 2), both of which include exon 1a. TM311 also recognized TM80, which contains the first 80 amino acids of chicken striated $\alpha$-TM (slot 3) and TM32, which contains just the first 32 amino acids of encoded by exon 1a (slot 4). TM311, however, did not recognize TM35 or TM43, both of which contain only the first 14 residues of exon 1a of $\alpha$-TM followed by a modified coiled-coil sequence (slots 5 and 7 ). Finally, TM311 did not bind to a peptide corresponding to TM residues 30-44 encoded by exon $1 \mathrm{~b}$, present in the low molecular weight TMs (slot 6). This epitope mapping showed that the monoclonal anti-TM TM311 recognizes an epitope in the region of residues 14-32 encoded by exon 1a of the rat $\alpha$-TM gene.

Immunoblot analysis of tissue lysates from embryonic and postnatal brains showed that both E16 and P10 brains contained three TM311-immunoreactive bands (Fig. $1 B$ ). This pattern of immunoreactivity is similar to that reported by Stamm et al. (1993). All three TM bands were present in whole embryos, embryonic 


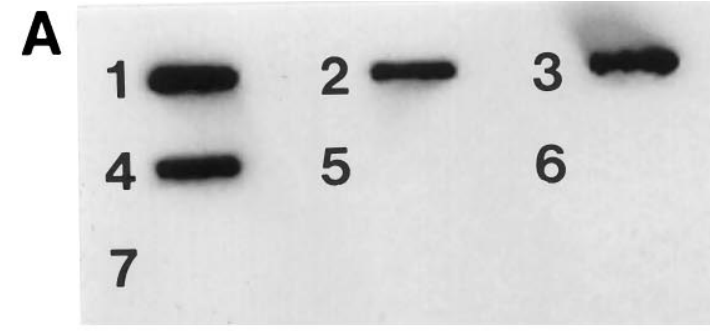

B

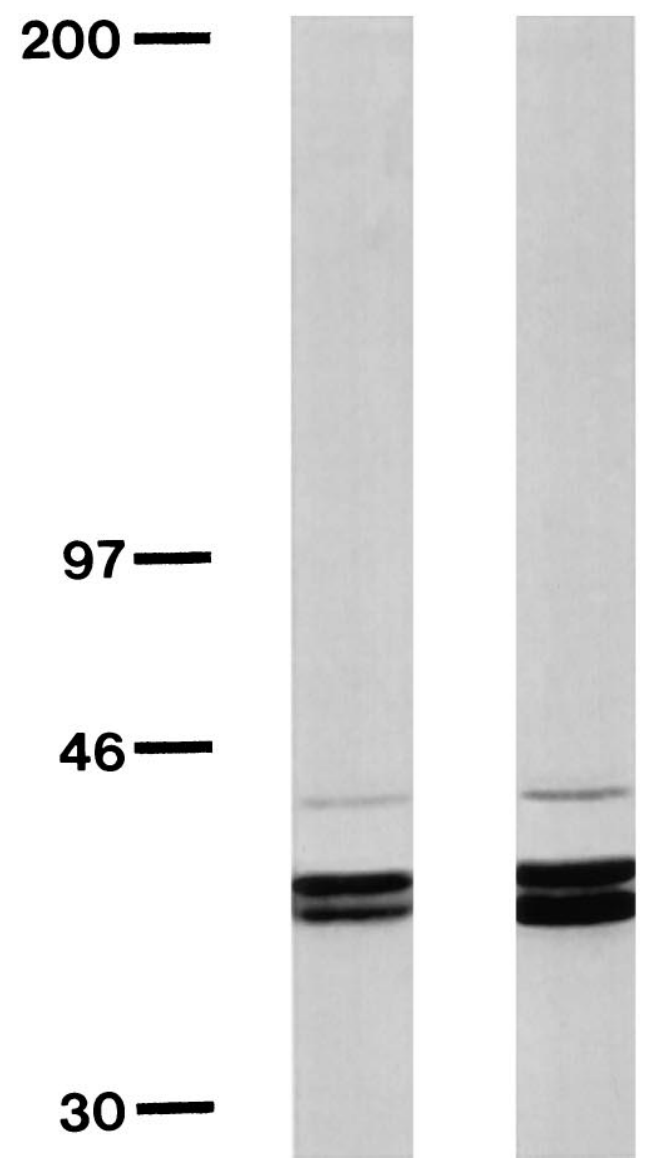

Figure 1. Characterization of monoclonal anti-tropomyosin antibody, clone TM311. $A$, The epitope recognized by TM311 is contained within residues $14-32$ of exon 1 of the $\alpha$-TM gene. A slot blot of 7 proteins or peptides corresponding to various regions of the protein encoded by the $\alpha$-TM gene was probed with TM311. This antibody recognizes recombinant striated rat $\alpha$-TM (slot 1 ), recombinant smooth rat $\alpha$-TM (slot 2), TM80, which contains the first 80 residues of chicken $\alpha$-TM (slot 3), and TM32, which contains the first 32 residues of exon 1a of rat $\alpha$-TM (slot 4). This antibody does not cross-react with TM35 or 43, which both contain only the first 14 residues of exon 1a of rat $\alpha$-TM followed a modified coiled-coil sequence (slots 5,7), or a peptide corresponding to residues $30-44$ of exon $1 \mathrm{~b}$ of rat $\alpha$-TM (slot 6 ). B, Immunoblot of E16 and P10 brain tissue lysates probed with TM311. Three TM-immunoreactive bands are evident. Molecular weight markers are indicated at the left (in $\mathrm{kDa}$ ).

brains, postnatal brains, and adult brains (data not shown). No additional bands were observed in the embryonic tissue lysates, indicating that we mapped TMs in both embryonic and postnatal brains. TM311 will recognize any TM that contains exon 1a. There are many TM isoforms, from both the $\alpha$ - and the $\beta$-TM genes, that have been cloned in the rat and contain exon 1a (for review, see Lees-Miller and Helfman, 1991). In the brain, the following high molecular weight TM isoforms are known to be present and would be recognized by this antibody: smooth $\alpha$ - and $\beta$-TM, present in the smooth muscle of blood vessels; TM-2, present in astrocytes (Had et al., 1993); and TMBr-1, present in neurons (Weinberger et al., 1996) and astrocytes (Had et al., 1993). Based on studies in other organisms, there are likely to be more TMs, including brain-specific isoforms, that have not yet been reported in the rat (Forry-Schaudies and Hughes, 1991). TM311 will not recognize TMs that contain exon $1 \mathrm{~b}$, such as the low molecular weight, brain-specific TMs TMBr-2 and TMBr-3. Although the exact isoforms present in neuroepithelial cells are not known at this time, labeling of early embryos with TM311 permits unambiguous identification of the high molecular weight TM class. We found selective expression in cells comprising distinct regions of the neuroepithelium, including all rhombomere boundaries, some prosomere boundaries, and morphogenetically active regions of the neuroepithelium, including the presumptive choroid plexus.

\section{Rhombomere boundaries are labeled by TM311}

At E10, the earliest age examined and corresponding to the onset of rhombomere formation in the rat, TM311 specifically labeled the cells that form the boundaries between rhombomere segments in the hindbrain (Fig. 2A,B). The TM311-immunoreactive cell bodies extended across the entire width of the neuroepithelium from the ventricular to the pial surfaces (Fig. 2B). TM311 immunoreactivity was expressed in each boundary that is morphologically evident. Figure $2 A$ shows four TM311-labeled boundaries and a more posterior boundary that is just forming. Faint TM immunoreactivity was observed in this latter boundary in adjacent sections, indicating that TM expression occurs at the onset of morphological segmentation in the hindbrain. The specific pattern of TM immunoreactivity was maintained at E11 (Fig. 2C,D), when strong TM311 labeling of all rhombomere boundaries was observed.

At E12, the appearance of the boundary regions changed (Fig. $2 E, F)$. The TM311-labeled zones remained discrete, but at this time the region, which exhibited a characteristic delta shape, contained darkly labeled cell bodies at the ventricular surface with slender processes extending to the pial surface (Fig. $2 F$ ). The boundary was approximately four to eight cells wide, similar to previous reports with localization of actin (Guthrie et al., 1991), a peanut lectin-binding epitope (Layer and Alber, 1990), and laminin (Lumsden and Keynes, 1989). Figure 2E highlights five TM311-immunoreactive boundaries between six rhombomeres in the E12 hindbrain. At all ages, whenever a boundary was morphologically evident TM311 labeling was seen in the cells present at that boundary. By E13, the morphological distinctions between rhombomeres began to disappear and, similarly, TM311 labeling of boundary cells lying between these segments was no longer present (data not shown). At all times, the nonboundary cells of the surrounding rhombomeres were virtually free of any TM311 immunolabeling, except for the smooth muscle cells of the blood vessels. In addition, TM311 immunoreactivity was observed in the mesenchyme surrounding the neuroepithelium and distributed throughout the embryo.

\section{TM311 labels boundaries between some prosomeres}

Given that TM311 specifically labeled boundaries between rhombomeres in the hindbrain, we investigated whether TM expression 

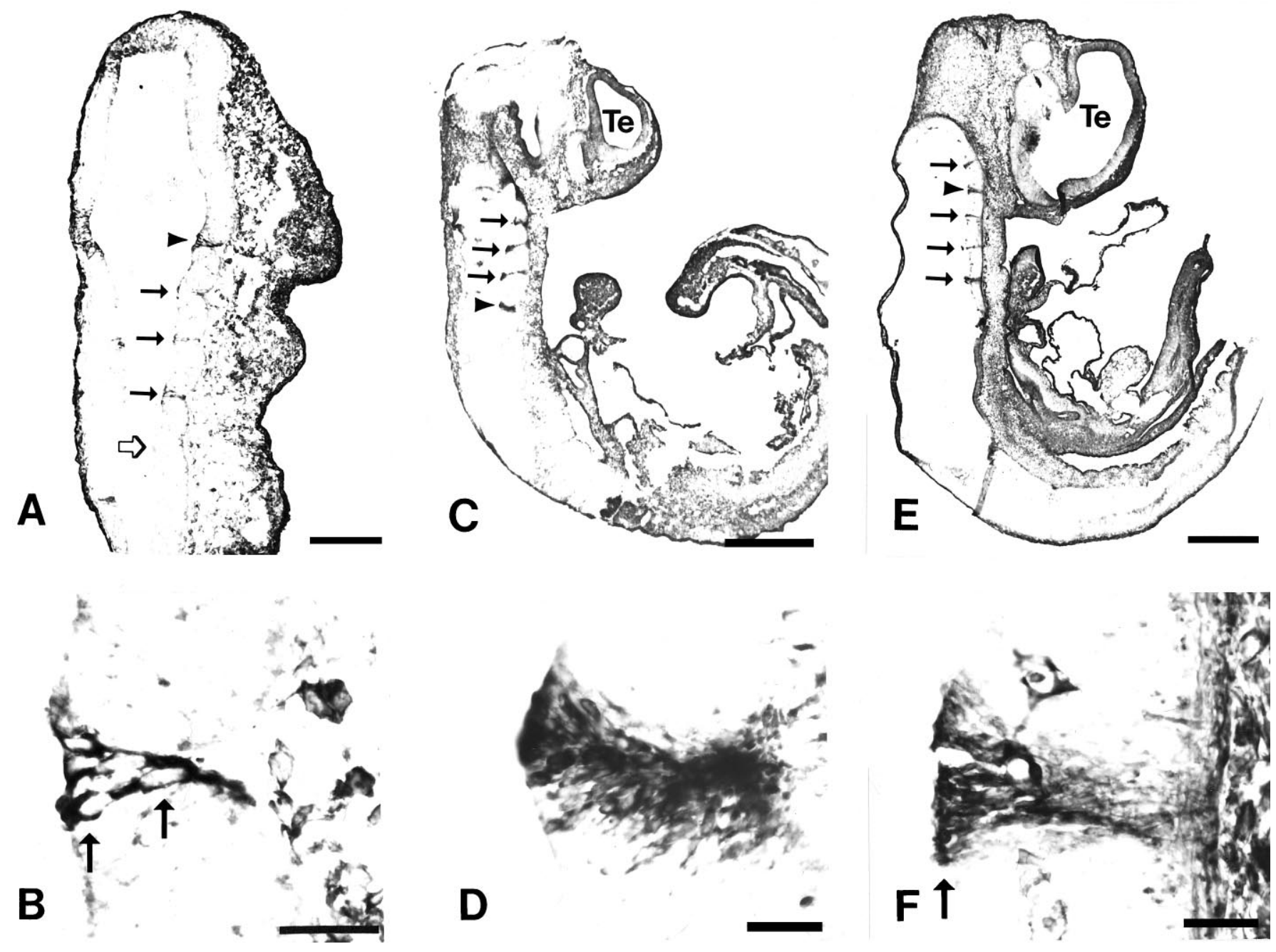

Figure 2. Tropomyosin is expressed at rhombomere boundaries in the developing rat hindbrain. Parasagittal sections at E10 $(A, B)$, E11 $(C, D)$, and E12 $(E, F)$ labeled with the anti-tropomyosin TM311 illustrate several TM311-immunoreactive boundaries between rhombomeres in the hindbrain ( filled arrows and arrowheads in $A, C, E$; boundaries shown at higher magnification in $B, D, F$ are indicated by arrowheads). At E10, corresponding to the onset of rhombomere formation, the boundaries are narrow and lightly immunoreactive compared to later ages. Open arrow in $A$ indicates a recently formed boundary that shows TM immunoreactivity in adjacent sections. Higher-magnification photomicrographs of individual rhombomere boundaries $(B, D, F)$ show that TM311-immunoreactive boundaries are 4-8 cells wide and that the cells extend across the width of the neuroepithelium. Arrows in $B$ and $F$ indicate locations of cell bodies. In the CNS, TM311 immunoreactivity is also evident in the smooth muscle of blood vessels and in connective tissue $(F)$. Scale bars: $A, 145 \mu \mathrm{m} ; B, D, E, 35 \mu \mathrm{m} ; C, E, 625 \mu \mathrm{m}$.

was specific to boundaries between prosomeres. Labeling of boundaries was observed in several locations, corresponding to the most morphologically distinct zones of neuroepithelium. There was a TM311-immunoreactive boundary between the pretectum and the tectum in the midbrain (Fig. $3 A, B$ ). The labeled cells were arranged in a delta shape and had darkly stained cell bodies at the ventricular surface with fine processes extending toward the pial surface, similar to boundary labeling in the hindbrain at this age (compare with Fig. $2 F$ ). The tectal-pretectal boundary was labeled by TM311 in only three to four adjacent, $10-\mu \mathrm{m}$-thick sections and corresponds to the caudal extent of the P1 prosomere as defined by Bulfone et al. (1993).

In a similar manner, TM-expressing cells marked the boundary between the dorsal and ventral thalamus. Again, this labeling, shown in the coronal plane (Fig. 3C,D), marked only the cells that form the boundary between the segments, whereas the neuroepithelial cells that make up the bulk of the dorsal and ventral thalamus were TM311-negative. This restricted cellular zone be- tween the dorsal and ventral thalamus, the zona limitans intrathalamica, corresponds to the boundary between the P2 and P3 prosomeres (Bulfone et al., 1993). The boundary between the ventral thalamic and hypothalamic regions of the diencephalon was also TM311-positive (Fig. 3C,D), although this boundary was not as discrete as that between the dorsal thalamus and ventral thalamus. The staining, however, highlights a distinction between the P3 and P4 prosomeres. The prosomere model includes the hypothalamus, or ventral secondary prosencephalon, within prosomeres P4, P5, and P6; thus, the P3-P4 boundary can be considered the distinction between the ventral thalamus and hypothalamus, or diencephalon from secondary prosencephalon (see Fig. $1 D$ of Puelles and Rubenstein, 1993). The examples mentioned here were the only locations in which TM311 labeled a discrete population of cells situated between prosomeres, which suggests that the high molecular weight TMs may regulate the distinct cell shapes associated with boundary cells in specific locations of the forebrain. All of these boundaries were labeled by TM311 at E12, 


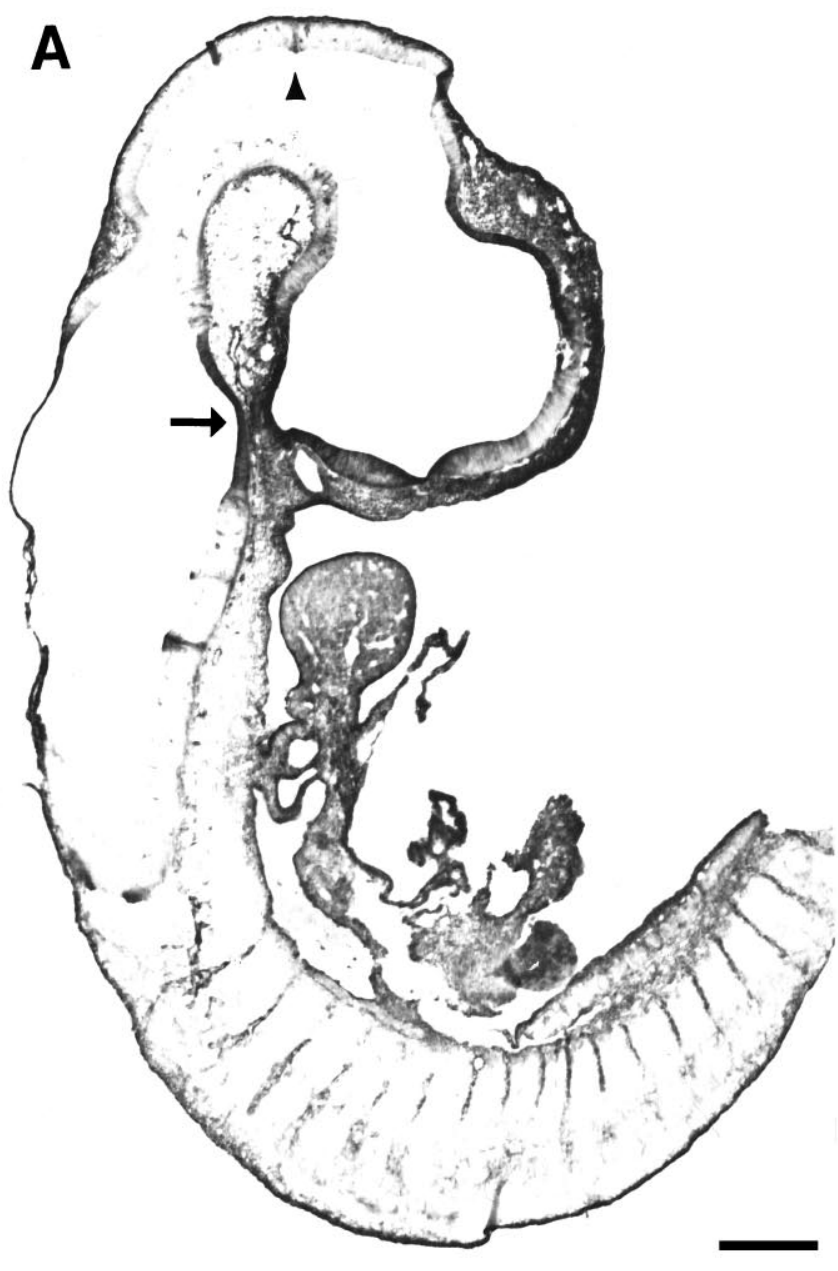

B

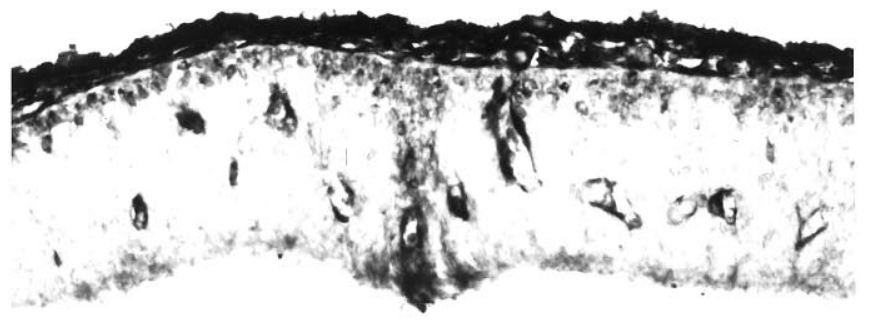

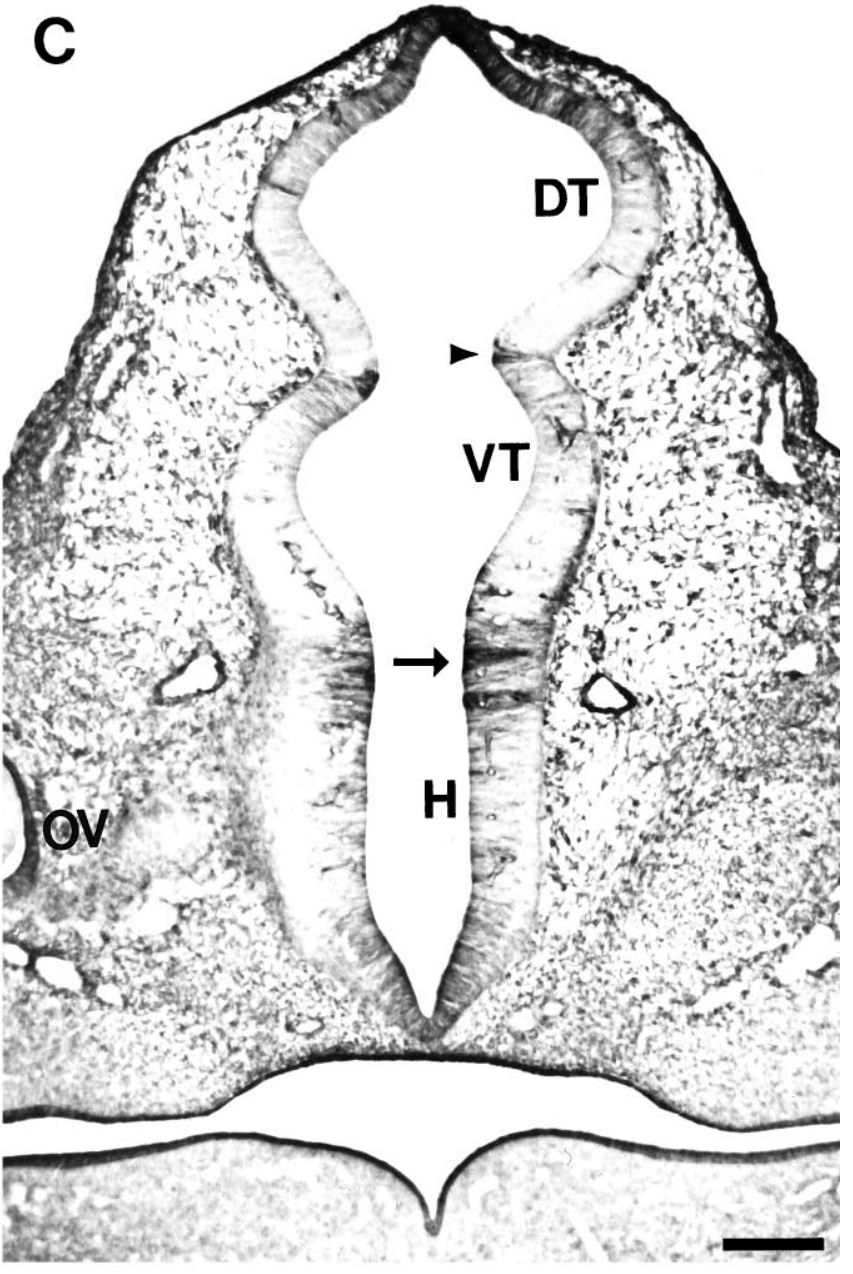

D

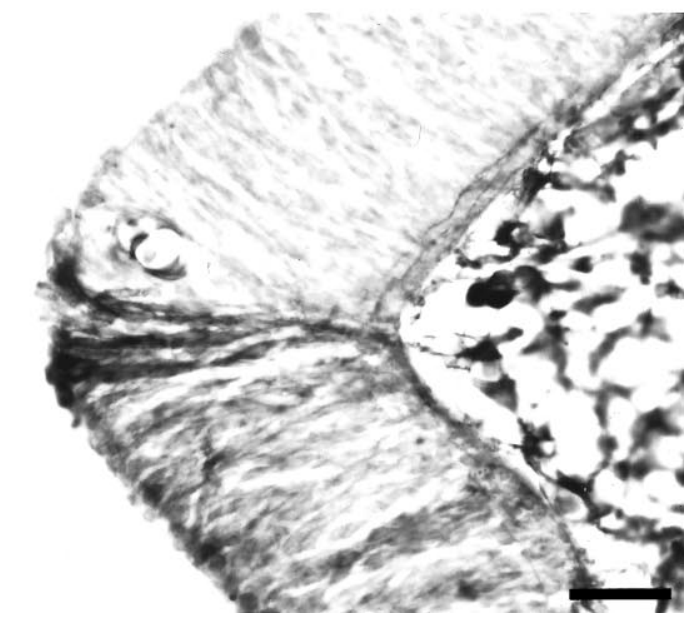

Figure 3. TM311 labels some prosomere boundaries. $A$, Midsagittal section through E12 rat showing TM311 immunoreactivity localized to the pretectum/tectum boundary (arrowhead). Note the TM immunoreactivity in dorsal root ganglia and intersomitic mesenchyme. $B$, Higher magnification of pretectum/tectum boundary (arrowhead in $A$ ), with TM311 immunolocalization that distinguishes the caudal boundary of prosomere P1. Note the blood vessel staining on either side of the TM311-positive boundary. $C$, Coronal section through E12 rat diencephalon at the level of the optic vesicle $(O V)$ showing TM311 immunolocalization at the boundary between the dorsal thalamus $(D T)$ and ventral thalamus (VT) (arrowhead, P2-P3 boundary). A boundary is also suggested between the VT and hypothalamus $(H$; arrow), contrasting the P3-P4 prosomeres. $D$, Increased magnification of TM311 immunolocalization at the zona limitans intrathalamica, the border between the DT and VT, a representation of the P2-P3 prosomeric boundary (arrowhead in $C$ ). Note the floor plate labeling in presumptive pons (arrow in $A$ ). Scale bars: $A, 470 \mu \mathrm{m} ; B, D, 50 \mu \mathrm{m} ; C, 150 \mu \mathrm{m}$. 

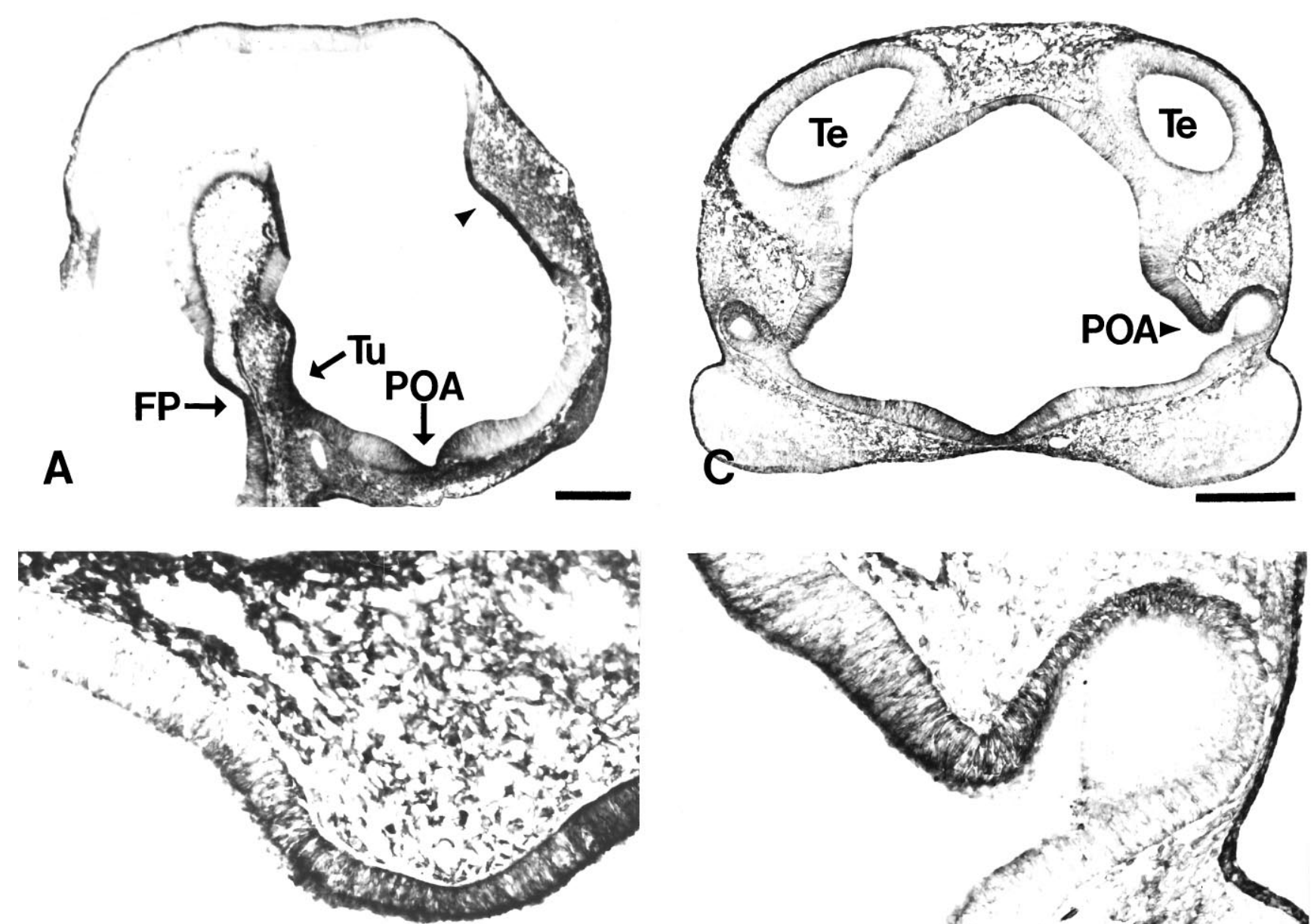

B

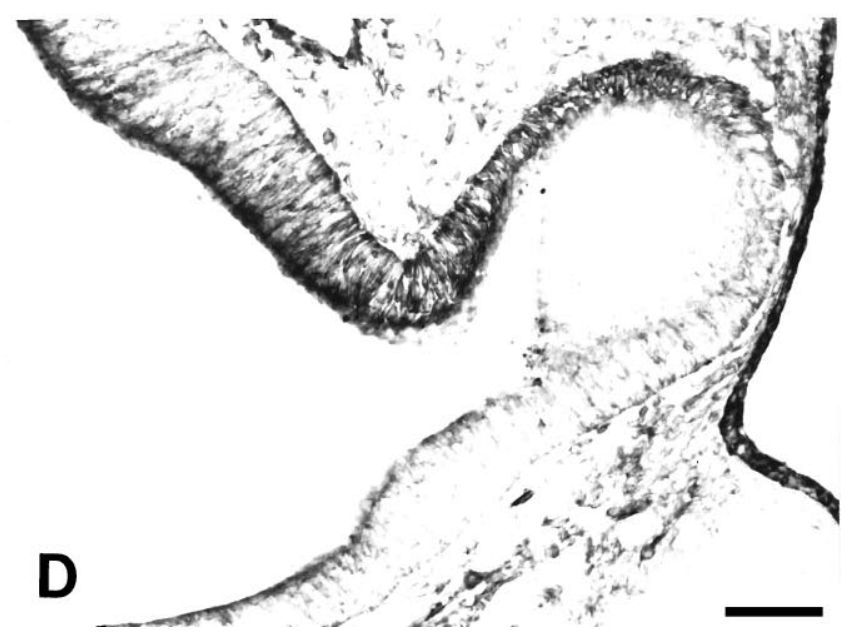

Figure 4. TM is localized to areas of the neuroepithelium that undergo extensive morphogenetic movements. $A$, Midsagittal section through an E12 rat showing TM immunolocalization in the tuberal (Tu), preoptic $(P O A)$, and presumptive choroid plexus neuroepithelium (arrowhead). Note floor plate $(F P)$ labeling in this section. $B$, Higher magnification of neuroepithelium containing the presumptive choroid plexus $($ arrowhead in $A)$, which is labeled before evagination. Note the well delineated boundary between TM311-positive and -negative neuroepithelium. $C$, Coronal section through E12 rat prosencephalon showing TM311 immunoreactivity in the preoptic neuroepithelium (POA; arrowhead). D, Higher magnification of the TM311-labeled preoptic neuroepithelium (arrowhead in $C$ ). Te, Telencephalic vesicle. Scale bars: $A, C, 350 \mu \mathrm{m} ; B, D, 65 \mu \mathrm{m}$.

but as the neuroepithelium folded further and neurogenesis proceeded, morphological boundaries became less evident and TM labeling of the boundary disappeared by E14.

Segmentation of the diencephalon has also been described by an alternative model (Figdor and Stern, 1993), in which the diencephalon has been divided into four segments. TM immunoreactivity is evident in the D1/D2 and D4/midbrain boundaries, which are characterized by morphologically evident ridges. The remaining boundaries in the Figdor and Stern (1993) model are defined by axon tracts that traverse that boundary at embryonic ages later than the TM labeling described here and, thus, TM immunolabeling was not observed in these boundaries.

\section{TM311 labels midline boundaries}

The roof and floor plate are comprised of cells with shapes distinct from surrounding neuroepithelium. In the hindbrain, we noted that a region in the presumptive pons was labeled with TM311 (Fig. 3A). Examination of adjacent sections revealed that the zone is very narrow (three to four $10-\mu \mathrm{m}$-thick sections) and is situated in the midline. This corresponds to TM311 labeling of the floor plate of the neural tube. In fact, TM expression was present in the ventral midline neuroepithelium and in the roof- and floorplate at all levels of the neural tube (Figs. $4 C, 5 C, E$ ) (data not shown).

\section{Evaginating neuroepithelium expresses TM}

TM311 labeled three large areas of the neuroepithelium that undergo dramatic morphogenetic movements at E12 (Fig. 4A). First, the preoptic area was heavily labeled with TM311 at the time this region is evaginating to form the optic cup (Fig. $4 A, C, D)$. Second, the tuberal epithelium of the hypothalamus, which migrates down to surround Rathke's pouch to form the pituitary, was labeled with TM311 (Fig. 4A). Third, a zone of the neuroepithelium that appears to contribute to the choroid plexus strongly expressed TM (Fig. 4A,B). This latter region of the neuroepithelium migrates out into the lateral ventricles to form the epithelial component of the choroid plexus. All of these regions demonstrated strong immunoreactivity across the width of the neuroepithelium.

The TM-expressing regions also highlighted distinctions between adjacent prosomeres. First, the TM311-positive tuberal 
epithelium contrasts with the less densely labeled anterior hypothalamus, distinguishing between the alar and basal domains of prosomere P5 (Fig. 4A). Second, the tuberal (TM311-positive) to mammillary (TM311-negative) epithelium change in TM expression highlights the boundary between prosomeres P4 and P5 (Fig. $4 A$ ). Third, the distinction between the presumptive choroid plexus (TM-positive) and the TM-negative thalamus that lies posterior to it corresponds to prosomeres $\mathrm{P} 2$ and $\mathrm{P} 3$ differences (Fig. 4A,B). Finally, the preoptic area is intensely TMimmunoreactive, whereas the cells of the developing anterior hypothalamus exhibit much less TM311 immunoreactivity (Fig. $4 A, C, D)$, corresponding to a distinction between the P5 and P6 prosomeres.

\section{TM311 appears to mark neuroepithelial choroid plexus precursors}

TM311 labeled a discrete domain of cells in the dorsal neuroepithelium that is generally defined as presumptive allocortex (Fig. $4 A, B)$. Analysis of a series of midsagittal, parasagittal, and coronal sections through the telencephalon and diencephalon at different ages, however, revealed that the TM311 immunoreactivity marks a region that appears to contain the neuroepithelial forerunners of the choroid plexus. As early as E11, almost $3 \mathrm{~d}$ before expansion of the choroid plexus into the lateral ventricles (Das, 1979; Altman and Bayer, 1995), TM311-labeled cells are apparent at the dorsal midline of the telencephalon (Fig. $5 A, B$ ), before the downfolding of the neuroepithelium to form the medial telencephalic walls. Coronal sections through the telencephalon at E12 show the intense TM311 immunoreactivity in cells just before the onset of choroid plexus formation (Fig. $5 C, D$ ). This region corresponds to the neuroepithelium shown in the parasagittal plane (Fig. 4A,B). In the coronal plane, it is evident that the darkly labeled cells at the ventral-most part of the medial cerebral wall are distinct from the TM311-negative cells comprising the dorsomedial neuroepithelium.

The expression of high molecular weight TMs was maintained at E14 and E16 in the neuroepithelium that appears to migrate into the lateral ventricles to become the choroid plexus (Fig. $5 E-H)$. At this age, the TM311 immunoreactivity was present not only in the epithelial cells of the choroid plexus proper, but in a restricted region of neuroepithelial cells in the ventral-most part of the telencephalic wall. The immunolabeling of the choroid precursors in the medial wall was most intense at the ventricular surface, but is present in fine processes extending throughout the width of the neuroepithelium. TM labeling also was observed in the connective tissue underlying the epithelium. Beyond E16, the region of TM311-labeled cells adjacent to the choroid plexus decreased.

In the hindbrain, at all ages examined, the velum medulare and the directly adjacent neuroepithelial cells, thought to be cerebellar precursors, were TM311-positive, whereas the remaining presumptive cerebellar neuroepithelium was TM311-negative. When we followed the pattern of labeling through development, it was evident that the TM-immunoreactive cells appear to contain the forerunners of the choroid plexus of the fourth ventricle (data not shown). TM311 also labeled the region containing the precursors of the choroid plexus of the roof of the third ventricle. In all areas, TM311 continued to label the choroid plexus as it formed during fetal development.

\section{Allocortical and choroid plexus precursors are derived from distinct cell populations}

The differential labeling with TM311 in the ventromedial wall of the dorsal telencephalon suggested that there is an early spatial segregation of the neuroepithelial cells that form the choroid plexus from those that give rise to the allocortex. To support this, we performed double-labeling experiments with TM311 and MAP2 at E15. MAP2 is a marker that labels neurons, such as those in the primordial plexiform layer of the allocortex (Fig. 6). TM311 immunolabeling was similar to that seen in Figure $5 E-H$, with TM immunolabeling present in the choroid plexus itself and in the apposed ventral neuroepithelium of the medial wall of the telencephalon. The TM311 immunoreactivity was complementary to MAP2 at all ages examined. The differential labeling of the cells in this region shows that the neuroepithelium in the medial telencephalic wall is spatially segregated to give rise to functionally distinct cell populations.

\section{DISCUSSION}

\section{Tropomyosin marks many boundaries in the developing rat CNS}

The mechanisms regulating the formation of boundaries between neuroepithelial zones during embryonic development remain unknown, but the present study serves as a first indication that the microfilament-regulatory protein TM may play an important role. High molecular weight tropomyosins are expressed in cells that occupy boundaries between rhombomeres in the hindbrain from E10 to E13, throughout the period during which rhombomeres are present, whereas the neuroepithelium of the segments themselves exhibits no TM immunoreactivity. Furthermore, we identified three zones in which TM marks only the boundary region between prosomeres, with the cells appearing similar to those stained at rhombomere boundaries. TM has a well established role in regulating actomyosin function and actin filament dynamics in both muscle and nonmuscle cells (Lees-Miller and Helfman, 1991; Pittenger et al., 1994). The expression of high molecular weight TMs in cells that form morphologically distinct boundaries between hindbrain segments and regions of the forebrain indicates a conserved mechanism of regulation of cell shape and/or motility for establishing some CNS boundaries. It will be interesting to learn whether TM expression absolutely precedes rhombomere formation and whether it follows the precise temporal sequence of rhombomere formation as reported for Fgf-3 in the chick (Mahmood et al., 1995). Absolute identification of specific rhombomeres, however, is normally carried out with whole-mount staining and is difficult with sectioned early embryos, because of embryonic flexion. Whole-mount immunocytochemistry is impossible with TM311, because of high levels of TM expressed by non-neural tissues. It is important to emphasize that forebrain boundaries identified by others on the basis of molecular differences, but without distinct morphological appearance, did not express high molecular weight TMs. This indicates that TM isoforms are not associated with all embryonic boundaries but, rather, a large subset that is unique, based on both the organization of discrete sets of neuroepithelial cells in narrow zones and the molecular differences between surrounding cell regions.

It has been suggested that the unique structure of hindbrain segments is generated because of a higher rate of cell division in the rhombomeres, whereas the boundary cells divide more slowly, leading to a bulging of rhombomeric neuroepithelium (Guthrie et al., 1991). It is possible that boundary cells are nonmotile and remain tethered to produce the morphologically evident ventric- 


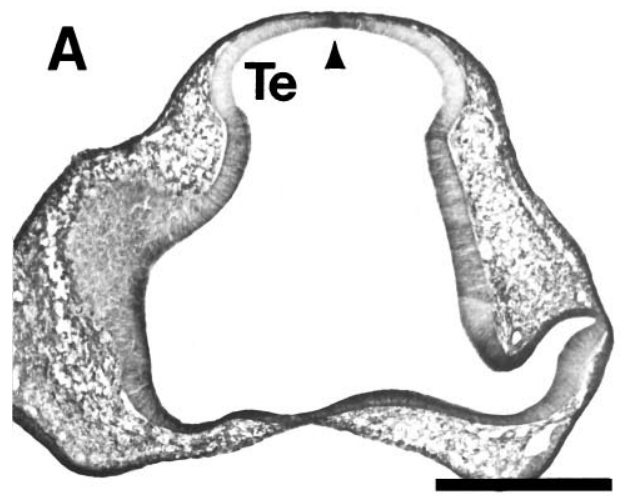

B
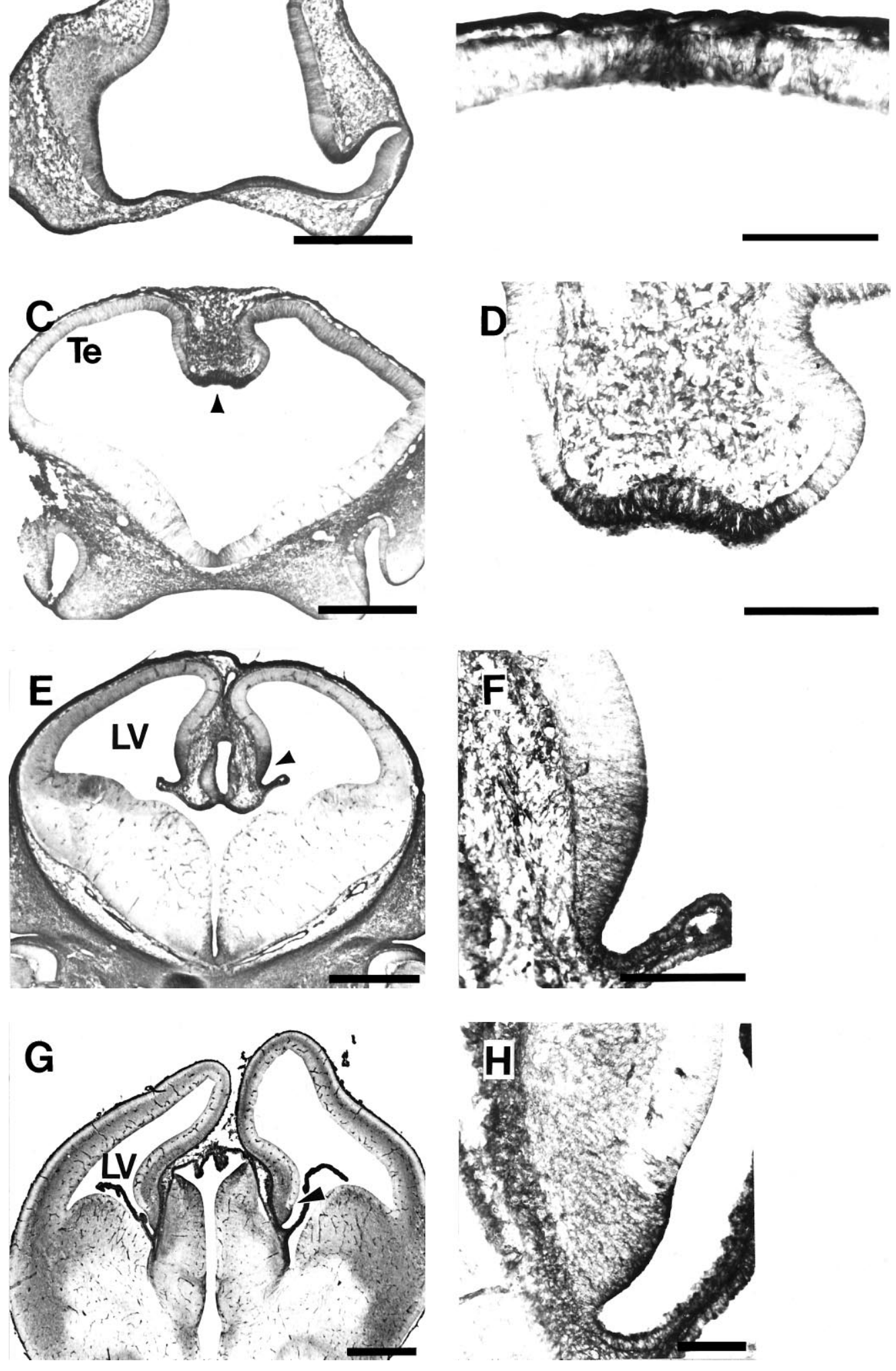


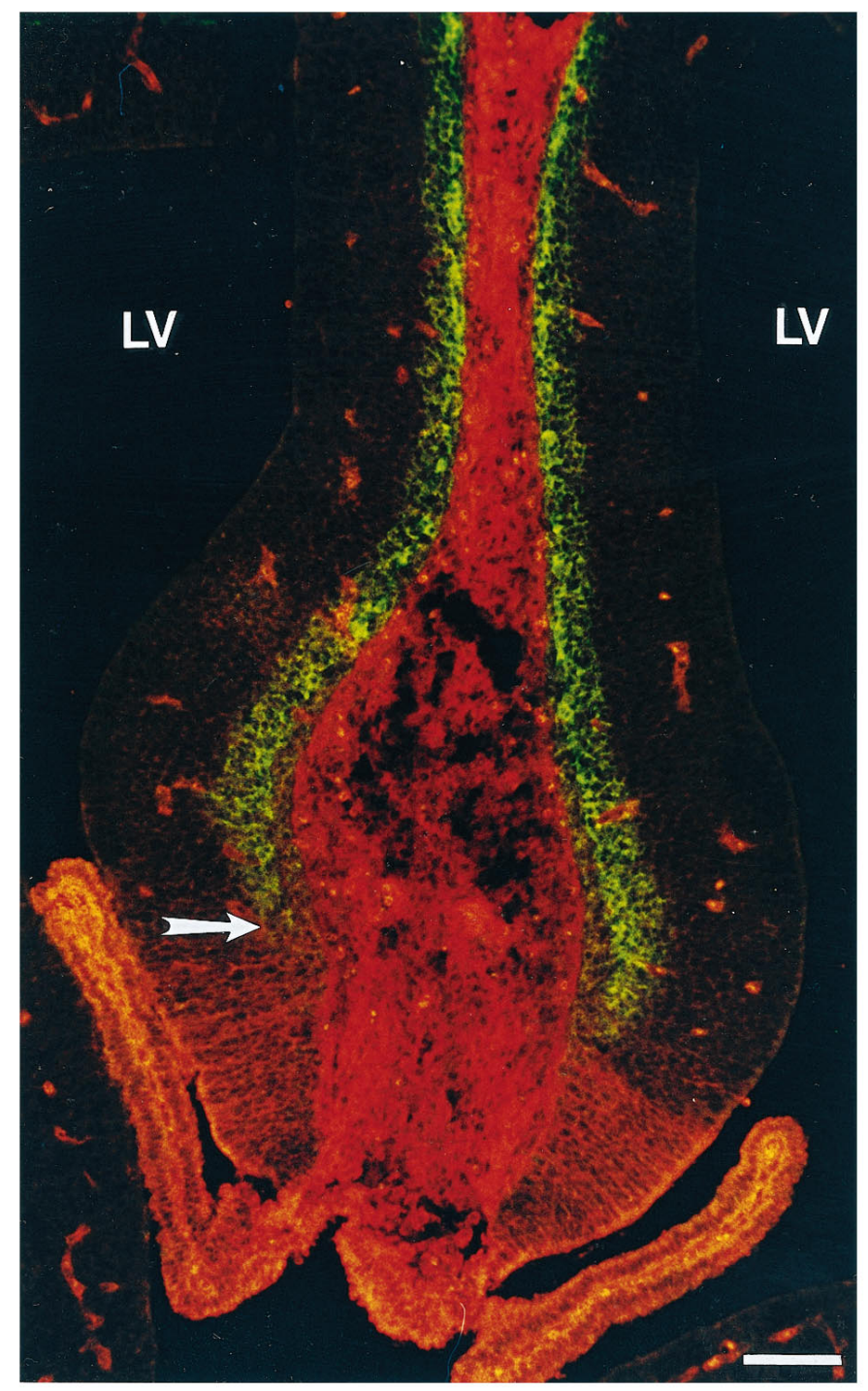

Figure 6. Color photomicrograph highlighting the molecular distinction between neuroepithelium-containing choroid plexus and allocortical precursors. Coronal section through E15 rat telencephalon reveals the sharp boundary (arrow) between the region containing the TM311-labeled presumptive choroid plexus (ventrally, in red) and allocortex, shown by MAP2-positive neurons in the primordial plexiform layer (dorsally, in green). TM is also expressed in the smooth muscle of the blood vessels and in connective tissue. Scale bar, $40 \mu \mathrm{m}$.

ular ridges. The high molecular weight TMs have been shown to reduce the flexibility of actin filaments (Fujime and Ishiwata, 1971) and to protect F-actin from severing and depolymerization (Hitchcock et al., 1976; Bernstein and Bamburg, 1982; Fattoum et al., 1983; Broschat, 1989, 1990). Interestingly, the low molecular weight TMs, not examined in this study but potentially present in some TM311-negative cells, have been associated with highly motile regions of cells, such as the ruffling membranes of fibroblasts (Lin et al., 1988). Although high molecular weight TMs are often associated with more stable microfilaments, it must be emphasized that the precise role of TM in nonmuscle cells, including the TM311-immunoreactive neuroepithelial cells in this study, remains unclear. It also is important to note that, based on TM311 staining, high molecular weight TMs are localized throughout boundary cells, suggesting that TM regulation of cellular processes other than apical constriction is involved in generating segment boundaries.

The mechanism regulating TM expression at boundaries is unclear. Anterior limits of expression of many hox genes fall along rhombomere boundaries, consistent with the possibility that TM expression is transcriptionally regulated by these genes. Regulation, however, is unlikely to occur through a single hox gene (or even simple combination), because no single hox gene is present in all cells of every boundary region. Fgf-3, however, was described recently in rhombomere boundary cells during or soon after boundary formation in the developing chick brain (Mahmood et al., 1995). Fgf-3 expression is induced early in boundary regeneration experiments, suggesting that this molecule may regulate boundary cell identity, possibly including TM expression. The promyelocytic leukemia zinc finger (PLZF) transcription factor also is highly expressed at rhombomere boundaries (Cook et al., 1995). This restricted expression occurs at E10 in a mouse, later than the initial expression of TM at E10 in the rat, making it an unlikely candidate for transcriptional regulation of $\mathrm{TM}$ at rhombomere boundaries.

\section{TM311 labels morphogenetically active regions of the neuroepithelium}

In contrast to the exclusive labeling of boundary cells demonstrated in both hind- and forebrain, we also identified TM311-labeling of morphogenetically active zones that highlight distinctions between prosomeres. For example, the tuberal hypothalamus (P5) is TM311positive, whereas the mammillary epithelium $(\mathrm{P} 4)$ is negative. These patterns are similar to those shown with differential hybridization with probes to homeobox genes, nonhomeobox transcription factors, and other differentiation factors (Bulfone et al., 1993, 1995; AlvarezBolado et al., 1995; Avantaggiato et al., 1995).

Although it is plausible that specific isoforms of cytoskeletal proteins would be expressed by cells in regions of the neuroepithelium undergoing morphogenetic movements, we did not anticipate that these regions would correspond to precise prosomeric organization. The regionalization of the forebrain is not typically emphasized based on pronounced morphological characteristics, but zones of neuroepithelial cells clearly undergo movements that contribute to telencephalic differentiation. The observed pattern of TM expression suggests an important role for TM in aspects of

Figure 5. Tropomyosin immunolabels cells that are the forerunners of the choroid plexus. $A$, Coronal section through E11 rat showing TM311immunolabeled cells (arrowhead) at the dorsal midline of the telencephalon (Te) that will form the choroid plexus $2-3 \mathrm{~d}$ later. $B$, Higher magnification of the restricted zone of TM311-labeled neuroepithelium (arrowhead in $A$ ). C, Coronal section through E12 rat telencephalon showing intensely TM311-immunoreactive cells (arrowhead) at the ventral-most region of the medial wall of the dorsal telencephalon. These cells will form the choroid plexus of the lateral ventricles. $D$, Higher magnification of the TM311-immunoreactive choroid plexus precursors (arrowhead in $C$ ). $E$, Coronal section through E14 rat showing TM311-labeled choroid plexus (arrowhead) of the lateral ventricle $(L V)$. $F$, Higher magnification showing TM311-labeled cells of the presumptive choroid plexus (arrowhead in E) distinguished from the TM311-negative presumptive allocortex. Note that the plexus has already formed in the LV and is TM311-positive (lower right side). G, Coronal section through the E16 rat telencephalon showing TM311-immunoreactive choroid plexus and choroid plexus precursors (arrowhead). $H$, Increased magnification showing TM311-positive cells of the developing choroid plexus at the ventro-medial wall of the dorsal telencephalon. Scale bars: $A, C, E, G, 500 \mu \mathrm{m} ; B, 100 \mu \mathrm{m} ; D, F, H, 200 \mu \mathrm{m}$. 
regulation of forebrain morphogenesis. It is important to note that TM311-labeled cells are located in regions of the neuroepithelium that actively evaginate as epithelial sheets rather than through individual cell movements. Furthermore, cells express TM before their actual migration, as observed with the choroid plexus. This expression may reflect the necessity for neuroepithelial cells to regulate microfilament structure collectively at the onset of evagination. TM has been localized previously to regions where epithelial cells migrate or contract in unison, such as in the "purse string" mechanism of wound healing (Bement et al., 1993) and in the terminal web of intestinal epithelium (Mooseker, 1976; Burgess, 1982). Many of the studies regarding the role of microfilaments in folding of the neural epithelium suggest that apical constriction of microfilament bundles drives the morphogenetic process (Burnside, 1971; Karfunkel, 1971). As we report here for both the hindbrain and the forebrain, TM immunostaining is not restricted to the apical region of the neuroepithelial cells, suggesting that TM regulates microfilament dynamics other than apical constriction.

\section{TM expression and choroid plexus formation}

The dorsomedial telencephalic wall often is designated as generating exclusively allocortex (Bulfone et al., 1993; Altman and Bayer, 1995). The TM expression pattern reported in this study suggests that this region contains two distinct precursor populations, the ventral-most of which appears to give rise to the choroid plexus. These precursor cells demonstrate TM immunoreactivity as early as E11 (Fig. 5), almost $3 \mathrm{~d}$ before the choroid plexus can be identified morphologically in the rat lateral ventricle. The generation of the epithelial component of the choroid plexus has been investigated with $\left[{ }^{3} \mathrm{H}\right] \mathrm{TdR}$ injections, and heavily labeled cells were found in the third and fourth ventricles of the mouse after injection at E12 (Miale and Sidman, 1961; Rakic and Sidman, 1968). Similar studies in the rat have shown that generation of the ependyma occurs along a caudal-to-rostral gradient, beginning at E14 (Das, 1979). The early TM expression is maintained in a segregated population of neuroepithelial precursors and the choroid plexus epithelium throughout fetal development. Other proposed markers for early choroid plexus include transthyretin, but its mRNA is localized only to the choroid plexus structure itself (Thomas et al., 1988; Makover et al., 1989; Cavallaro et al., 1993). TM311 labeling is thus far the earliest marker of the choroid plexus, and it probably reflects an important role for microfilament regulation in formation of this structure.

The segregation of allocortical neuronal and choroid plexus precursors, based on our analysis of MAP2 and TM311 double immunolabeling, is evident as early as E13 and throughout all other ages evaluated (E13-E16). In fact, labeling of the dorsomedial prosencephalic wall at E11, before telencephalic vesicle formation, indicates an early molecular distinction in this neuroepithelium, where only a part is dedicated to generating cells that will comprise allocortex (Bulfone et al., 1993; Altman and Bayer, 1995). The early expression of TM indicates an important role in microfilament regulation during initial stages of precursor sequestration. The continued expression of TM in choroid plexus cells that actively migrate out into the ventricles also implicates TM regulation in morphogenetic movements associated with evagination of the choroid plexus throughout development. It is unclear, however, which genes might regulate this segregation, because none of the transcription factors examined thus far, either separately or in combination, specifically marks this early, TM-positive region of midline epithelium.
The discrete regulation of the expression of high molecular weight TMs in the early developing rat CNS suggests a central role in modulating actin filament dynamics. The control of such dynamics, based on our understanding of non-neural epithelium, is likely to be critical for folding regions of the neuroepithelium and maintenance of border regions in the neural tube during embryonic growth. The present study provides the first indication that microfilament regulation by TM is a central component of neuroepithelial specialization.

\section{REFERENCES}

Altman J, Bayer SA (1995) Atlas of prenatal rat brain development. Boca Raton, FL: CRC.

Alvarez-Bolado G, Rosenfeld MG, Swanson LW (1995) Model of forebrain regionalization based on spatiotemporal patterns of POU-III homeobox gene expression, birthdates, and morphological features. J Comp Neurol 355:237-295.

Avantaggiato V, Pandolfi PP, Ruthardt M, Hawe N, Acampora D, Pelicci G, Simeone A (1995) Developmental analysis of murine promyleocyte leukemia zinc finger (PLZF) gene expression: implications for the neuromeric model of the forebrain organization. J Neurosci 15:4927-4942.

Bement WM, Forscher P, Mooseker MS (1993) A novel cytoskeletal structure involved in purse string wound closure and cell polarity maintenance. J Cell Biol 121:565-578.

Bernstein BW, Bamburg JR (1982) Tropomyosin binding to F-actin protects the F-actin from disassembly by brain actin-depolymerizing factor (ADF). Cell Motil 2:1-8.

Berod A, Hartman BK, Pujol JF (1981) Importance of fixation in immunohistochemistry: use of formaldehyde solutions at variable $\mathrm{pH}$ for localization of tyrosine hydroxylase. J Histochem Cytochem 29:844-850.

Birgbauer E, Fraser SE (1994) Violation of cell lineage restriction compartments in the chick hindbrain. Development 120:1347-1356.

Boulder Committee (1970) Embryonic vertebrate central nervous system: revised terminology. Anat Rec 166:257-261.

Broschat KO (1990) Tropomyosin prevents depolymerization of actin filaments from the pointed end. J Biol Chem 265:21323-21329.

Broschat KO, Weber A, Burgess DR (1989) Tropomyosin stabilizes the pointed end of actin filaments by slowing depolymerization. Biochemistry 28:8501-8506.

Bulfone A, Puelles L, Porteus MH, Frohman MA, Martin GR, Rubenstein JLR (1993) Spatially restricted expression of $D l x-1, D l x-2$ (Tes-1), $G b x-2$, and $W n t-3$ in the embryonic day 12.5 mouse forebrain defines potential transverse and longitudinal segmental boundaries. J Neurosci 13:3155-3172.

Burgess DR (1982) Reactivation of intestinal epithelial cell brush border motility: ATP-dependent contraction via a terminal web contractile ring. J Cell Biol 95:853-863.

Burnside B (1971) Microtubules and microfilaments in newt neurulation. Dev Biol 26:416-441.

Cavallaro T, Martone RL, Stylianopoulou F, Herbert J (1993) Differential expression of the insulin-like growth factor II and transthyretin genes in the developing rat choroid plexus. J Neuropathol Exp Neurol 52:153-162.

Cho Y-J, Hitchcock-DeGregori SE (1991) Relationship between alternatively spliced exons and functional domains in tropomyosin. Proc Natl Acad Sci USA 88:10153-10157.

Cook M, Gould A, Brand N, Davies J, Strutt P, Shaknovich R, Licht J, Waxman S, Chen Z, Gluecksohn-Waelsch S, Krumlauf R, Zelent A (1995) Expression of the zinc-finger gene PLZF at rhombomere boundaries in the vertebrate hindbrain. Proc Natl Acad Sci USA 92:2249-2253.

Cote GP, Smillie LB (1981) The interaction of equine platelet tropomyosin with skeletal muscle actin. J Biol Chem 256:7257-7261.

Das GD (1979) Gliogenesis and ependymogenesis during embryonic development of the rat: an autoradiographic study. J Neurol Sci 43:193-204.

Fattoum A, Hartwig JH, Stossel TP (1983) Isolation and some structural and functional properties of macrophage tropomyosin. Biochemistry 22:1187-1193.

Ferri RT, Levitt P (1993) Cerebral cortical progenitors are fated to produce region-specific neuronal populations. Cereb Cortex 3:187-198. Figdor MC, Stern CD (1993) Segmental organization of embryonic diencephalon. Nature 363:630-634. 
Fischer I, Kosik KS, Sapirstein VS (1987) Heterogeneity of microtubuleassociated protein (MAP2) in vertebrate brains. Brain Res 436:39-48.

Forry-Schaudies S, Hughes SH (1991) The chicken tropomyosin 1 gene generates nine mRNAs by alternative splicing. J Biol Chem 266:13821-13827.

Fraser S, Keynes R, Lumsden A (1990) Segmentation in the chick embryo hindbrain is defined by cell lineage restrictions. Nature 344:431-435.

Freeman JA, Cheshire LB, MacRae TH (1992) Epithelial morphogenesis in developing Artemia: the role of cell replication, cell shape change, and the cytoskeleton. Dev Biol 152:279-292.

Fujime S, Ishiwata S (1971) Dynamic study of F-actin by quasielastic scattering of laser light. J Mol Biol 62:251-265.

Greenfield NJ, Hitchcock-DeGregori SE (1993) Conformational intermediates in the folding of a coiled-coil model peptide of the N-terminus of tropomyosin and $\alpha \alpha$-tropomyosin. Protein Sci 2:1263-1273.

Greenfield NJ, Stafford WF, Hitchcock-DeGregori SE (1994) The effect of $\mathrm{N}$-terminal acetylation on the structure of an $\mathrm{N}$-terminal tropomyosin peptide and $\alpha$-tropomyosin. Protein Sci 3:402-410.

Guthrie S, Butcher M, Lumsden A (1991) Patterns of cell division and interkinetic nuclear migration in the chick embryo hindbrain. J Neurobiol 22:742-754.

Had L, Faivre-Sarrailh C, Legrand C, Mery J, Brugidou J, Rabie A (1994) Tropomyosin isoforms in rat neurons: the differential developmental profiles and distributions of $\mathrm{TM}-4$ and $\mathrm{TMBr}-3$ are consistent with different functions. J Cell Sci 107:2961-2973.

Hannan AJ, Schevzov G, Gunning P, Jeffrey PL, Weinberger RP (1995) Intracellular localization of tropomyosin mRNA and protein is associated with development of neuronal polarity. Mol Cell Neurosci 6:397-412.

Hendricks M, Weintraub H (1981) Tropomyosin is decreased in transformed cells. Proc Natl Acad Sci USA 78:5633-5637.

Hitchcock SE, Carlsson L, Lindberg U (1976) Depolymerization of F-actin by deoxyribonuclease I. Cell 7:531-542.

Kam Z, Minden JS, Agard DA, Sedat JW, Leptin M (1991) Drosophila gastrulation: analysis of cell shape changes in living embryos by threedimensional fluorescence microscopy. Development 112:365-370.

Karfunkel P (1971) The role of microtubules and microfilaments in neurulation in Xenopus. Dev Biol 25:30-56.

Krumlauf R, Marshall H, Studer M, Nonchev S, Sham MH, Lumsden A (1993) Hox homeobox genes and regionalisation of the nervous system. J Neurobiol 24:1328-1340.

Laemmli UK (1970) Cleavage of structural proteins during the assembly of the head of bacteriophage T4. Nature 227:680-685.

Layer P, Alber R (1990) Patterning of chick brain vesicles as revealed by peanut agglutinin and cholinesterases. Development 109:613-624.
Lees-Miller JP, Helfman DM (1991) The molecular basis for tropomyosin isoform diversity. Bioessays 13:429-437.

Lin JJ-C, Hegmann TE, Lin JL-C (1988) Differential localization of tropomyosin isoforms in cultured nonmuscle cells. J Cell Biol 107:563-572.

Lumsden A, Keynes R (1989) Segmental patterns of neuronal development in the chick hindbrain. Nature 337:424-428.

Mahmood R, Kiefer P, Guthrie S, Dickson C, Mason I (1995) Multiple roles for FGF-3 during cranial neural development in the chicken. Development 121:1399-1410.

Makover A, Soprrano DR, Wyatt ML, Goodman DS (1989) An in situhybridization study of the localization of retinol-binding protein and transthyretin messenger RNAs during fetal development in the rat. Differentiation 40:17-25.

Matsumura F, Yamashiro-Matsumura S (1985) Purification and characterization of multiple isoforms of tropomyosin from rat cultured cells. J Biol Chem 260:13851-13859.

Miale IL, Sidman RL (1961) An autoradiographic analysis of histogenesis in the mouse cerebellum. Exp Neurol 4:277-296.

Mooseker MS (1976) Brush border motility: microvillar contraction in triton-treated brush borders isolated from intestinal epithelium. J Cell Biol 71:417-433.

Olson L, Seiger A (1972) Early prenatal ontogeny of central monoamine neurons in the rat: fluorescence histochemical observations. Z Anat Entwicki-Gesch 137:301-316.

Pittenger MF, Kazzaz JA, Helfman DM (1994) Functional properties of non-muscle tropomyosin isoforms. Curr Opin Cell Biol 6:96-104.

Puelles L, Rubenstein JLR (1993) Expression patterns of homeobox and other putative regulatory genes in the embryonic mouse forebrain suggest a neuromeric organization. Trends Neurosci 16:472-479.

Rakic P, Sidman RL (1968) Subcommissural organ and adjacent ependyma: autoradiographic study of their origin in the mouse brain. Am J Anat 122:317-336.

Rubenstein JLR, Martinez S, Shimamura K, Puelles L (1994) The embryonic vertebrate forebrain: the prosomeric model. Science 266:578-580.

Stamm S, Casper D, Lees-Miller JP, Helfman DM (1993) Brain-specific tropomyosins TMBr-1 and TMBr-3 have distinct patterns of expression during development and in adult brain. Proc Natl Acad Sci USA 90:9857-9861.

Thomas T, Power B, Hudson P, Schreiber G, Dziadek M (1988) The expression of transthyretin mRNA in the developing rat brain. Dev Biol 125:415-427.

Weinberger R, Schevzov G, Jeffrey P, Gordon K, Hill M, Gunning P (1996) The molecular composition of neuronal microfilaments is spatially and temporally regulated. J Neurosci 16:238-252. 